\title{
Role of Serine Proteases and Host Cell Receptors Involved in Proteolytic Activation, Entry of SARS-CoV-2 and Its Current Therapeutic Options
}

\section{Gashaw Dessie (D) \\ Tabarak Malik}

Department of Biochemistry, School of Medicine, College of Medicine and Health Sciences, University of Gondar, Gondar, Ethiopia
Correspondence: Gashaw Dessie

Tel +25l 975I52796

Email dessiegashaw@yahoo.com

\begin{abstract}
The current global pandemic of a novel severe acute respiratory syndrome coronavirus- 2 continues with its public health disaster beginning from late December 2019 in Wuhan, Hubei province, China. The scientific community has tried to fight against this novel coronavirus through vaccine development and designing different candidate drugs. However, there is no well-defined therapy to prevent 2019-nCov infection, thus complete prevention of the virus remains difficult. Therefore, it is a critical factor for death of millions worldwide. Many clinical trials and insights are ongoing in the struggle with this pandemic of SARS-CoV-2. SARS-CoV-2 entry into the host cell requires host cell angiotensinconverting enzyme-2 (ACE2) and glucose regulated protein 78 (GRP78). On the other hand, proteolytic activation of the viral spike protein (S protein) needs the host cell serine proteases, including transmembrane serine protease 2 (TMPRSS2), cathepsins, trypsin and furin. This review focuses on the protein involved in the mechanism of entry, and proteolytic activation. In addition, it looks at current therapeutic options for SARS-CoV-2.
\end{abstract}

Keywords: SARS-CoV-2, proteolytic activation, viral entry

\section{Introduction}

Severe acute respiratory syndrome coronavirus-2 (SARS-CoV-2) is a global health pandemic, which originated and was disseminated from Wuhan, in the Chinese province of Hubei, and it causes millions of death worldwide. ${ }^{1}$ The spike protein (S protein) of coronavirus is a structural surface glycoprotein, which is responsible for host-virus membrane fusion, binding of receptor and pathogenesis of virus. ${ }^{2}$ It is composed of carboxyl intracellular terminus, transmembrane domain and N-terminal extracellular domain. ${ }^{3}$ Spike glycoprotein consists of S1 and S2 subunits having a binding and hostviral membrane fusion activity, respectively. It facilitates viral entry into the host cell, and it is encoded by all types of coronavirus. However, the receptor binding domain (RBD) of $S$ protein facilitates a viral-host receptor interaction specific to beta coronavirus subtypes. ${ }^{4}$ The cleavage of S2 and S1 subunits at the boundary site causes a conformational change for membrane fusion of the virus and the host cells. ${ }^{5}$ Host cell surface receptor, angiotensin-converting enzyme 2 (ACE2) is recognized by the SARS-CoV-2 S1 subunit of spike protein that contains $\mathrm{RBD}^{6}$ The activity of vital host-cell receptor, ACE2 is activated by androgen-dependent enzyme, including transmembrane protease serine 2 (TMPRSS2), thus a recent therapeutic strategy plan depends on blocking the activity of this cellular receptor. ${ }^{7}$ Studies revealed that ACE2 is a determinant factor for the entry of 
SARS-CoV-2 rather than TMPRSS2 because the expression of TMPRSS2 is limited to a specific organ. ${ }^{8}$

Cellular entry of SARS-CoV-2 also depends on the activity of serine proteases, such as TMPRSS2 at PH-independent state. ${ }^{9}$ Fusion of SARS-CoV-2 requires proteolytic cleavage of spike glycoprotein at the boundary of S1 and S2 subunits. The priming of S protein depends on the activity of host cell proteases and it induces conformational changes in those subunits. ${ }^{10}$ Studies showed that the activation of spike protein requires the activity of TMPRSS2 to cleave it. ${ }^{11}$ On the other hand, the fusion of viral-host membrane requires furinbased priming at the $\mathrm{S} 1 / \mathrm{S} 2$ site of S protein, hence proteolytic cleavage at this site induces the activity of TMPRSS2 to facilitate entry of SARS-CoV-2. ${ }^{12}$ The $\mathrm{S}$ protein of SARS$\mathrm{CoV}-2$ consists of $\mathrm{S} 1$ and $\mathrm{S} 2$ cleavage sites required for the purpose of proteolytic activation induced by furin. ${ }^{13}$ Studies state that effective priming of $\mathrm{S}$ protein of virus is activated by furin and it facilitates entry of the virus. ${ }^{14}$ In addition to TMPRSS2 and furin, cathepsins induce endocytic-based fusion of host cell and viral membrane. ${ }^{15}$ Although the activity of cathepsin has been well-studied in MERS-CoV and SARS-CoV-2, its potential role still needs further investigation. However, the investigation done on 293T cells having ACE2 showed that the entry of the virus was decreased by $76 \%$ in cathepsin $\mathrm{L}$ inhibitor treated pseudo virus. ${ }^{1}$ Inhibition of the activity of cathepsin $\mathrm{B} / \mathrm{L}$ by elevating endosomal $\mathrm{pH}$ leads to reduce the entry of SARS-CoV-2 in 293T cells. ${ }^{16}$ In addition to this, the other cellular protease promotes the activation of S protein to facilitate viral entry into the host cell. ${ }^{17}$ It has a similar effect with TMPRSS2 regarding cleavage of S protein of SARS-CoV-2. ${ }^{9}$

\section{Proteins Involved in Viral Entry Mechanism}

\section{Angiotensin-Converting Enzyme 2 Mediated SARS-CoV-2 Entry}

Tissues express exopeptidase angiotensin-converting enzyme 2 (ACE2) to activate the binding of SARS-CoV-2 spike glycoprotein to host cell receptors. ${ }^{18}$ The expression of ACE2 is not only associated with the lung, but also with extra-pulmonary tissues, which indicates the possible dissemination of virus to other tissues. ${ }^{19}$ Dissemination of the virus to the lungs, gastrointestinal tract, kidneys, and heart indicates the expression of ACE2 in those vital organs. ${ }^{20}$ A recent investigation done on Chinese pigs, civets, and bats showed that HeLa cells having ACE2 surface receptors were infected with SARS-CoV-2. ${ }^{21}$ Studies had correlated and confirmed the binding interaction of ACE2 with former SARS-CoV and current SARS-CoV-2 S protein. Therefore, they notified the presence of the same model interaction. ${ }^{22}$ Thus, SARS-CoV-2 entry to the host cell depends on the presence of ACE2 on the host cell membrane. ${ }^{23}$ The investigation done on animal models showed that the severity of SARS-CoV infection is associated with elevated expression of this cellular surface receptor. ${ }^{24}$

Inhibition of binding interaction of $\mathrm{ACE} 2$ and $\mathrm{S}$ protein requires down-regulation of ACE2 host cell receptor. However, ACE2 undergoes endocytosis through angiotensin II type 1 receptor (AT1R) to facilitate its physiological and biological action within the cell. Thus, downregulating the expression of ACE2 has its own complications in lungs. ${ }^{25}$ The role of ACE2 in the entry mechanism of SARS-CoV-2 has similar activity to the former SARS$\mathrm{CoV}$, thus RBD of spike glycoprotein binds to ACE2. ${ }^{26}$ The receptor binding domain found on $\mathrm{S} 1$ subunit of $\mathrm{S}$ protein is vital for the binding of ACE2 to the virus. ${ }^{27}$ Binding interaction of ACE2 to RBD region of S protein is a determinant factor for entry of the virus to the host cell ${ }^{28}$ (Figure 1). The receptor binding domain consists of 318-510 amino acid residues that are responsible for binding with ACE2. ${ }^{29}$ In vivo experimental studies done in China revealed that ACE2 is recognized by A475 and F486 amino acid residues found in RBD of S protein. ${ }^{28}$ In addition to viral entry, the transmission of the virus among humans is also associated with tight binding of S protein with ACE2. ${ }^{5}$

\section{Glucose Regulated Protein 78 Mediated SARS-CoV-2 Entry}

Cellular stress condition is a factor for the release of glucose regulated protein 78 (GRP78) from endoplasmic reticulum and its exportation to cell membrane, which in turn leads to entry mechanism of SARS-CoV-2. ${ }^{30}$ Recent data predicted that the binding and entry activity of the virus is related to the interaction of $\mathrm{S}$ protein with membrane bounded protein, including GRP78. ${ }^{31}$ Binding of SARS-CoV-2 to GRP78 is expected to be facilitated by a molecular docking mechanism that occurs through the interaction between GRP78 substrate binding domain region and region IV of this novel coronavirus. ${ }^{32}$ The molecular docking model (HADDOCK software) utilized by researchers revealed that SARS-CoV-2 $\mathrm{S}$ protein residue at $\mathrm{C} 480-\mathrm{C} 488$ was responsible for binding with GRP78, and they identified more than four interaction sites between GRP78 and viral S protein. ${ }^{33}$ Similarly, 


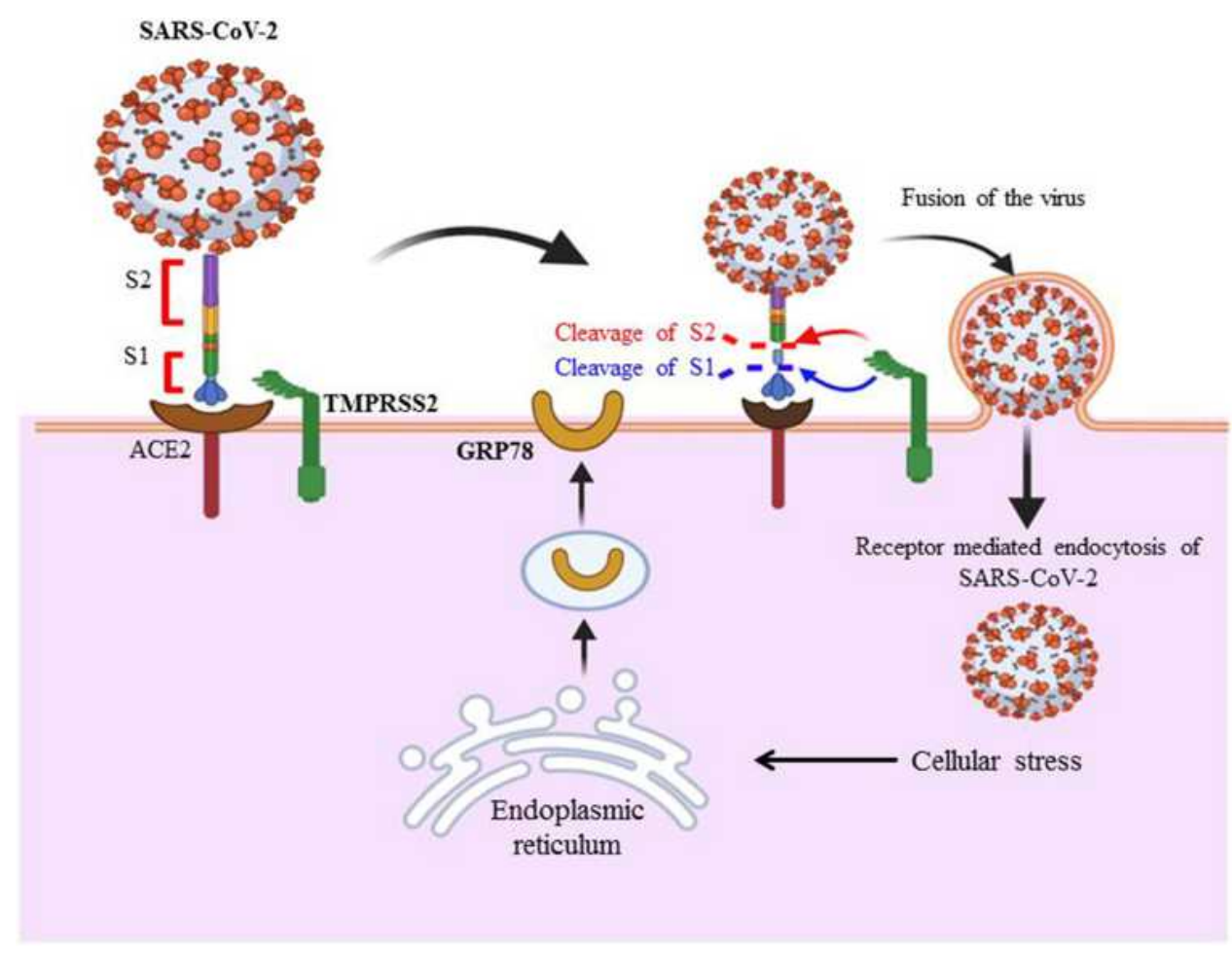

Figure I S glycoprotein of SARS-CoV-2 binds to host cell receptors (ACE2, TMPRSS2 and GRP78) found in human lung epithelial cells to facilitate entry mechanism of the virus. These host cellular receptors areexpressed in various tissues including human lung cells, kidney and gastrointestinal tract. The binding interaction of ACE2 to RBD region of $\mathrm{S}$ protein is a determinant factor for entry of the virus to host cell. Cleavage of $\mathrm{S}$ protein through host cell proteases is also required for further fusion of viral and host cell membrane. After the virus enters the host cell through receptor mediated endocytosis, cellular stress condition leads to the exportation of GRP78 for further activation and interaction of virus with host cell. The infection of virus is not limited to human epithelial cells of the lungs since ACE2 expressed in different tissues including kidneys, heart, liver, retina and enterocytes of the intestines and other tissues throughout the body. This indicates the possible tropism of virus in various tissues. Note: Figure created with Biorender.com.

Abbreviations: ACE2, angiotensin-converting enzyme 2; GRP78, glucose regulated protein 78; RBD, receptor binding domain; TMPRSS2, transmembrane serine protease 2; SARS-CoV-2, severe acute respiratory syndrome coronavirus-2; S protein, spike glycoprotein.

researchers confirmed that $\mathrm{S}$ protein of virus may interact with GRP78 in a head-to-head fashion in the III and IV regions of substrate binding domain of GRP78. ${ }^{30}$ In addition to GRP78, multi-walled carbon nanotube mechanistic studies attempted to identify the binding activity of SARS-CoV-2 of RBD-ACE2 complex (6LZG) and main viral proteases (6LU7) and they confirmed the presence of strong binding activity between ACE2 and viral S protein RBD. ${ }^{34}$

Endoplasmic reticulum (ER) stress increases in SARSCoV-2 infected cells, which in turn activates an unfolded protein response. Storage of unfolded protein within ER leads to the release of GRP78 to activate the enzymes such as inositol requiring enzyme 1 (IRE1), protein kinase RNAlike endoplasmic reticulum kinase (PERK) and activating transcription factor 6 (ATF6) to refold and synthesize protein. $^{35}$ The level of GRP78 becomes elevated as a result of unfolded protein response activity within ER. ${ }^{36}$ Law and his coworkers in 2020 revealed that the genetic expression of
GRP78 increased because ER stress is caused by the influence of SARS-CoV-2 S protein. ${ }^{37}$ Elevated levels of GRP78 and $\mathrm{S}$ protein within endoplasmic reticulum (ER) in turn affect unfolded protein response. ${ }^{38}$ Thus, the cellular stress condition leads to the exportation of GRP78 to the plasma membrane to activate virus-host binding interaction and activate the viral entry mechanism ${ }^{39}$ (Figure 1). Studies notified that inhibition of GRP78 ATPase activity using celecoxib derivative, AR12 (OSU-03012) may act as a possible therapeutic option to diminish its protein renaturation capability and decrease $\mathrm{S}$ protein synthesis. ${ }^{40}$

\section{Transmembrane Serine Protease 2 Mediated SARS-CoV-2 Entry}

Transmembrane serine protease 2 (TMPRSS2) is a host cellgenerated protease capable of priming $\mathrm{S}$ protein to activate the binding of the SARS-CoV-2 to ACE2 because it consists of the extracellular domain utilized for virus-receptor interaction. ${ }^{23}$ 
In addition to other host cell proteases, TMPRSS2 is a major protease for SARS-CoV-2 infection, and invasion of human lung cells. ${ }^{41}$ ACE2 is the main cellular surface receptor involved in the SARS-CoV-2 entry mechanism. ${ }^{42}$ After the virus binds to ACE2 of the host cell, TMPRSS2 activates priming and fusion of virus-host cell membrane, which also leads to the entry of the virus to the host cell ${ }^{43}$ (Figure 1). The $\mathrm{S}$ protein of coronavirus consists of $\mathrm{S} 1$ and $\mathrm{S} 2$ subunits having RBD and membrane fusion functional elements, respectively. Transmembrane domain, hepatid and fusion peptides are the main components of S2 subunit of CoV S protein. ${ }^{44}$ Although the multi-basic amino acid residues of S1/S2 of SARS-CoV-2 are undefined, it is found in other human coronaviruses, including MERS-COV, HKU1 and OC43. ${ }^{41}$ After binding of $\mathrm{S}$ protein of virus to ACE2, it undergoes conformational changes to be proteolytically degraded in the midpoint of S1 and $\mathrm{S} 2$ subunits by host cell proteases, including TMPRSS2. ${ }^{45}$ In addition to cathepsin B/L mediated endocytosis, cleavage of $\mathrm{S}$ protein by TMPRSS2 also activates the entry of SARS-CoV into host cells. ${ }^{46}$ Although the mechanism of TMPRSS2 induced activation of $\mathrm{S}$ protein is not well-defined, studies confirmed that TMPRSS2 mediates host cells and viral membrane fusion. ${ }^{47}$ Researchers revealed that fusion of plasma and viral membrane during the entry mechanism provokes TMPRSS2 to induce extracellular priming of $\mathrm{S}$ protein as the virus binds to ACE2. ${ }^{43}$ Transmembrane serine protease 2 activates and cleaves $S$ protein to induce infectivity and spread of the virus. ${ }^{18,43,44}$ It has a potential therapeutic insight after the identification of its impact on the pathogenesis of H7N9, H3N2 and H1N1 influenza A virus. ${ }^{1}$

\section{Proteins Involved During Proteolytic Activation of SARS-CoV-2 Spike Protein Cathepsins}

Cathepsins are members of various proteases that are involved in the antigen presenting process, and proteolytic activation. ${ }^{48}$ Proteolytic activation of coronavirus $\mathrm{S}$ protein activates the generation of a better conformational state for the purpose of receptor binding activity and virus-host cell membrane fusion. ${ }^{49}$ Recent investigations tried to assess proteases regarding cleavage of $\mathrm{S} 1 / \mathrm{S} 2$ site of $\mathrm{S}$ protein of SARS-CoV, and they showed that cathepsin B is capable of actively degrading $\mathrm{S} 1 / \mathrm{S} 2$ site of $\mathrm{S}$ protein. ${ }^{48}$ As TMPRSS2 acts on host-viral membrane fusion, cathepsin B/L undergoes their proteolytic activation after endocytosis of the virus. ${ }^{50}$ Cathepsins play a major role in the fusion of endosomal and viral membrane because they cause priming of $\mathrm{S}$ protein following endocytosis of the virus. ${ }^{43}$ The entry of $\mathrm{CoV}$ to the target cell depends on the cathepsin levels of these cells during the endocytosis process. ${ }^{51}$ The cathepsin found in the lysosome facilitates endocytic dependent entry of SARSCoV-2 to the host cell. ${ }^{52}$ Studies assessed the role of cathepsins for the entry mechanism of the virus, thus cathepsin L inhibitor (calpain (E64D)) and cathepsin L, B, H inhibitors were introduced to HEK 293/hACE2 cells. In this investigation, the introduction of cathepsin $\mathrm{L}$ to these cells induces a marked decline in the SARS-CoV-2 entry mechanism compared with cathepsin $\mathrm{B}^{51}$ In this regard, cathepsin $\mathrm{L}$ induces splitting of $\mathrm{S}$ protein to increase viral entry and infection. ${ }^{53}$ An investigation done on animals indicates that SARS-CoV-1 utilizes cathepsin-L for infection. ${ }^{54}$ Although inhibition of cathepsin L by calpain inhibitor XII is not clearly elucidated, studies notified that calpain inhibitor XII is an active inhibitor of cathepsin L. ${ }^{55}$

\section{Trypsin}

Trypsin is a serine endopeptidase, which is expressed mainly in respiratory and digestive cells and it acts as a digestive enzyme. $^{48}$ Although trypsin is not highly selective for cleavage sites on $\mathrm{S}$ protein, the arginine amino acid residues found in between $\mathrm{P} 6-\mathrm{P}^{\prime}$ region of $\mathrm{S}$ protein are mainly recognized and cleaved by it. ${ }^{56}$ It is an active protease that can be inhibited by a candidate drug, such as camostat. ${ }^{1}$ Even though the mechanism of proteolytic activation at the S1/S2 boundary and $\mathrm{S} 2{ }^{\prime}$ site is not well-defined, multi-basic S1/S2 site is essential for SARS-CoV-2 viral infection in the cells of the lung. ${ }^{15}$ Cleavage at the $\mathrm{S} 1 / \mathrm{S} 2$ site of SARS-CoV-2 $\mathrm{S}$ protein may be associated with priming due to trypsinlike protease activity. ${ }^{10}$ Both trypsin and TMPRSS2 are required for the activation of syncytium formation during SARS-CoV-2 S protein expression. Therefore, S1/S2 sites may be optimized for altered viral pathogenesis and invasion of the virus. ${ }^{41}$ In comparisons with various coronaviruses, the cleavage potential of trypsin had a higher efficiency for SARS-CoV-2 than other coronavirus subtypes. ${ }^{48}$

\section{Furin}

Furin is highly expressed in some tissues, including kidney, endocrine organ, and lungs as well as being expressed in moderate amounts in the gastrointestinal tract. ${ }^{57}$ Vankadari and Naveen in their 2020 preprint studies express furin as a $\mathrm{Ca} 2+$ dependent protease, which is highly expressed in lung cystic fibrosis disorder, and it is involved in the cleavage of SARS-CoV-2 viral glycoprotein. ${ }^{58}$ The availability of furinlike cleavage at $\mathrm{S} 1 / \mathrm{S} 2$ site of viruses, including SARS-CoV-2 
contributes to the pathogenesis of the virus. ${ }^{57}$ SARS-CoV-2 utilizes furin for the cleavage of S protein at the S1/S2 site. ${ }^{59}$ Furin induces priming of S protein at this site for the fusion of host cell membrane, and viral glycoprotein. ${ }^{57}$ The expression of furin in the trans-golgi network hypothesizes its possible involvement in the synthesis of viral S protein. In addition, it mediates multi-basic site cleavage of $\mathrm{S}$ protein of SARS-CoV $-2{ }^{60}$ Tang and his coworkers in their preprint studies in 2020 identified the presence of additional amino acid residue, P-R-R-A in SARS-CoV-2 at S1/S2 site that was not notified in SARS-CoV. ${ }^{61}$ R-R-A-R amino acid residue at the $\mathrm{S} 1 / \mathrm{S} 2$ site of $\mathrm{S}$ protein may be sensitive to furin dependent cleavage. ${ }^{62}$ The activity of furin resides on this poly basic motif to activate the degradation of S protein to generate S2 and S1 subunits. ${ }^{52}$ Comparison of the cleavage potential of both MERS-CoV and SARS-CoV-2 showed it was highly efficient for SARS-CoV-2 rather than MERS-CoV. ${ }^{63}$ This amino acid residue is a common nucleotide sequence for the substrate of furin and $\mathrm{S} 1 / \mathrm{S} 2$ site of the virus. Therefore, proteolytic activation of the $\mathrm{S} 1 / \mathrm{S} 2$ site by furin may lead to syncytium generation. ${ }^{64}$ Studies revealed that the fusion of SARS-CoV-2 in S1/S2 mutated $\mathrm{S}$ protein was elevated as compared with fusion with mutated furin cleavage activity. ${ }^{15}$

\section{Therapeutic Potential of Inhibiting Entry Mechanism and Proteolytic Activation}

The therapeutic strategy plan for human coronavirus depends on host-virus interaction to target host and viral protein of HCov-NL63, MERS-CoV, SARS-CoV, and HCOV-229E. ${ }^{65}$ Endoplasmic reticulum stress contributes to the pathogenesis of SARS-CoV-2 and it may be treated with pharmacological chaperones, including GRP78 to enhance protein folding in the ER, but this therapeutic strategy may take a long time. ${ }^{66}$ Studies correlated the level of GRP78 with ER stress. Studies confirmed GRP78 serves as a biochemical parameter to evaluate the level of ER stress. ${ }^{36}$ Thus, among SARS-CoV -2 infected study groups, the amount of GRP78 was elevated compared with the apparently healthy controls and SARSCOV-2 negative pneumonia patients. ${ }^{36}$ Studies done in Turkey hypothesize that cellular ER stress may be elevated because of significant elevation of GRP78 among SARSCoV-2 infected patients compared with healthy groups ${ }^{67}$ (Table 1). The therapeutic strategy of SARS-CoV-2 is effective by targeting ACE2 and GRP78 host cell surface receptors. ${ }^{68}$ The therapeutic strategic mechanism against GRP78 is associated with targeting SBD and nucleotide binding domain of GRP78. Thus, potent inhibitors including epigallocatechin gallate (EGCG) and various bioactipeptides (satpdb18674, satpdb18446, satpdb12488, satpdb14438, and satpdb28899) was tried to inhibit GRP78-S protein complex interaction. ${ }^{69}$ Serum protein level of GRP78 was analyzed using case-control observational study in Turkey among 144 adult patients (Table 1). COVID-19 patients showed higher levels of GRP78 compared with control groups and ER stress induces an elevated level of GRP78 ${ }^{67}$

Morbidity of SARS-CoV-2 was elevated in COVID-19 patients who took angiotensin-receptor blockers (ARBs) and angiotensin-converting enzyme inhibitors (ACEIs) because the expression of ACE2 is increased. ${ }^{70}$ Similarly, a descriptive study done in China indicates that the severity and infection of SARS-CoV-2 was elevated among chronic renal disease, coronary artery disease, diabetes and hypertensive patients who were under treatment of ACEIs or ARBs. ${ }^{25}$ These studies argue that the treatment outcomes induces the elevated expression of ACE2 in various tissues including heart, kidney and intestine and aggravates mortality and morbidity of SARS-CoV-2. On the contrary, the investigation done on animal models notified that ACE2 upregulated as ACEI/ARB demonstrated for therapy; however, ARB/ACEI blocked renin-angiotensin system may prevent COVID-19 illness or severity and it may act as a therapeutic option in COVID-19 patients. ${ }^{71}$ Safety of ACEI/ARB is under evaluation by observational cohort study design among 10,000 adult COVID-19 and hypertensive patients (clinicaltrial. gov, 2020) (Table 1). Although the inhibitors of viral protein are not well-defined and studied, the strategy of SARS-CoV -2 therapy can be associated with the binding interaction of $\mathrm{S}$ protein, E protein and $\mathrm{N}$ protein with $\mathrm{RBD} .{ }^{72}$ Inhibiting the binding of SARS-CoV-2 with ACE2 is a potential therapeutic strategy by blocking S1/S2 subunit of RBD of viral spike glycoprotein. ${ }^{73}$ The binding affinity of S protein to ACE2 elevated to 10 up to 20 times as compared with their binding interaction in the former SARS-CoV, so the therapeutic target of their interaction has greater potential. ${ }^{18}$ TMPRSS2 activates proteolytic cleavage of ACE2, which is a vital host cell receptor for SARS-CoV-2 entry. ${ }^{73}$

Studies done on mice indicate that DNA-vaccine development targeting the SARS-CoV-2 S protein inhibits the binding of ACE2 with viral S protein. ${ }^{74}$ DNA-based vaccine development is currently in preclinical and clinical stages to end this global pandemic. Researchers design vaccine development through the extraction of different forms of S protein of SARS-CoV-2, and they tried to evaluate the protective efficacy and immunogenicity of the virus in rhesus 
Table I Assessment of Some Current Therapeutic Agents and Vaccine Development Trials for SARS-CoV-2

\begin{tabular}{|c|c|c|c|c|c|c|}
\hline $\begin{array}{l}\text { Intervention/ } \\
\text { Treatment }\end{array}$ & Status & $\begin{array}{l}\text { Study } \\
\text { Location }\end{array}$ & $\begin{array}{l}\text { Targeting Mechanism of the } \\
\text { Drug/Intervention }\end{array}$ & Conditions & $\begin{array}{l}\text { NCT } \\
\text { Number }\end{array}$ & References \\
\hline \multicolumn{7}{|l|}{ Drugs } \\
\hline ER stress & Completed & Turkey & $\begin{array}{l}\text { ER stress evaluated as GRP78 level } \\
\text { elevated }\end{array}$ & $\begin{array}{l}\text { COVID-19 and } \\
\text { pneumonia }\end{array}$ & NCT04628637 & 36,67 \\
\hline GRP78 & Completed & Turkey & Serum protein level analysis & $\begin{array}{l}\text { COVID-19 and } \\
\text { endoplasmic } \\
\text { reticulum }\end{array}$ & NCT04628637 & 67 \\
\hline ACEI/ARB & $\begin{array}{l}\text { Active/not } \\
\text { recruiting }\end{array}$ & USA, Utah & $\begin{array}{l}\text { Block angiotensin-receptor and } \\
\text { inhibit angiotensin converting } \\
\text { enzyme-2 }\end{array}$ & $\begin{array}{l}\text { COVID-19 and } \\
\text { Hypertension }\end{array}$ & NCT0446793I & 71 \\
\hline Camostat & $\begin{array}{l}\text { Recruiting/ } \\
\text { phase I }\end{array}$ & $\begin{array}{l}\text { USA, } \\
\text { Connecticut }\end{array}$ & Inhibit protease activity of TMPRSS2 & COVID-19 & NCT04353284 & 83 \\
\hline Bicalutamide & $\begin{array}{l}\text { Recruiting } \\
\text { phase III }\end{array}$ & $\begin{array}{l}\text { USA, } \\
\text { Florida }\end{array}$ & $\begin{array}{l}\text { Inhibit/block protease activity of } \\
\text { TMPRSS2 }\end{array}$ & COVID-19 & NCT04509999 & 88 \\
\hline \multicolumn{7}{|l|}{ Vaccination } \\
\hline $\begin{array}{l}\text { Synthetic MVA based } \\
\text { SARS-COV-2 } \\
\text { Vaccine }\end{array}$ & $\begin{array}{l}\text { Recruiting } \\
\text { Phase I }\end{array}$ & $\begin{array}{l}\text { USA, } \\
\text { California }\end{array}$ & Spike protein & COVID-19 & NCT04639466 & 74,75 \\
\hline $\begin{array}{l}\text { Recombinant } \\
\text { vaccination }\end{array}$ & $\begin{array}{l}\text { Recruiting } \\
\text { Phase I }\end{array}$ & China & Spike protein & COVID-19 & NCT04636333 & 76,77 \\
\hline
\end{tabular}

Abbreviations: ACEI/ARB, angiotensin-converting enzyme inhibitor/angiotensin-receptor blockers; ER, endoplasmic reticulum; GRP78, glucose regulated protein 78; MVA, modified Vaccinia virus Ankara; SARS-CoV-2, severe acute respiratory syndrome coronavirus-2.

macaques. ${ }^{75}$ Regarding Th1 vs Th2 polarization, SARS-CoV -2-specific neutralizing antibodies and incidence of adverse events on a Synthetic MVA-based SARSCoV-2 Vaccine was assessed among 129 adult COVID-19 patients in the USA through placebo-randomized interventional clinical trial (clinicaltrial.gov, 2020) (Table 1). In addition to DNAbased vaccine, pre-clinical trials focus on the investigation of recombinant vaccination of $\mathrm{S}$ protein in various research institutions worldwide. ${ }^{76}$ A recombinant NVX-CoV2373 nanoparticle vaccine is a potential to evaluate the efficacy in Phase I and the safety of vaccine development in Phase II of the study. ${ }^{77}$ Efficacy of recombinant vaccine development is found at a phase I interventional randomized clinical trial among 216 adult Chinese COVID-19 patients (clinicaltrial. gov, 2020) (Table 1).

Studies done on animal models through 293 T cells showed that blockage of cathepsin L/B activity had their restriction on the entry of the virus to host cells. ${ }^{16}$ Studies notified that ER stress is a promising therapeutic strategy to interrupt viral pathogenesis and minimize apoptosis. ${ }^{37}$ The entry of coronavirus to the host cell may be blocked by targeting important host proteins, including ACE2 and TMPRSS2, because the former one is crucial for entry, whereas the latter one is critical for the fusion of host and viral membranes. ${ }^{78}$ Although there are no well-defined studies done on ACE2 inhibitors, promazine and emodin are expected to interfere with the binding interaction of ACE2 with viral S glycoprotein; however, the effect of these candidate drugs on ACE2-expressed tissue is not well-known. ${ }^{79}$ As compared with emodin, promazine is an active inhibitor of the interaction of ACE2 and SARS-CoV S glycoprotein. ${ }^{80}$ In addition to host cellular receptors, the viral $S$ protein also is a potential therapeutic target for vaccines, antibody generation and designation of inhibitors. ${ }^{81}$ The cleavage of $\mathrm{S}$ protein needs the activity of furin and TMPRSS2 priming at the $\mathrm{S} 1 / \mathrm{S} 2$ site of viral protein, hence they are a vital therapeutic strategy of serine protease inhibitors to treat the current pandemic of COVID-19. ${ }^{62}$

Protease inhibitor (camostat) is under clinical trials of Phases I-III beginning from April 2020 to inhibit protease 
activity of TMPRSS2; however, the specific target of this protease is not elucidated clearly yet. ${ }^{82}$ Clinical trials.gov registered three clinical trials regarding the efficacy of camostat against SARS-CoV-2 in different countries, including Germany, the USA and Denmark. ${ }^{83}$ Rubitecan, loprazolam, nafamostat and camostat are some approved drugs that are tried in the clinical trial of treatment of SARS-CoV-2. ${ }^{84}$ Transmembrane serine protease 2 is an active serine protease that can be inhibited by camostate mesylate, consequently fusion of host-viral membrane becomes blocked and diminishes entry of virus to host cells. ${ }^{85}$ In addition to TMPRSS2, the activity of ACE2 becomes reduced by camostat to inhibit virus-host binding interaction. ${ }^{86}$ The safety and efficacy of camostate are under investigation among 114 adult COVID-19 patients through placebo-interventional clinical trial in the USA (clinicaltrial.gov, 2020) (Table 1). The expression of mRNA TMPRSS2 is downregulated as a result of bicalutamide intervention among COVID-19 patients, which in turn leads to decreased infection of SARS-CoV- $2^{87}$ because genetic expression of TMPRSS2 is elevated by androgen receptors. The promoter region of mRNA TMPRSS2 contains 15 base pairs of androgen response elements. Therefore, androgen accounts for post-translational modification as well as transcriptional regulation of TMPRSS 2 mRNA. ${ }^{88}$ The safety and efficacy of bicalutamide are on Phase III-interventional randomized clinical trial among 100 adult COVID-19 patients in the USA (clinicaltrial.gov, 2020) (Table 1).

Furin-mediated proteolytic cleavage promotes the availability of amino acid motifs RRAR/S found on $\mathrm{S}$ protein of SARS-CoV-2. The cleavage at those amino acid residues leads to the fusion of host-cell and viral membrane. ${ }^{89}$ In addition to TMPRSS2 and furin, trypsin also contributes to the cleavage of $\mathrm{S}$ glycoprotein, which indicates a possible therapeutic target of SARS-CoV-2. ${ }^{90}$

\section{Conclusion}

Designing therapies for the current SARS-CoV-2 global pandemicis the major challenge of fighting against the virus. Various clinical insights and trials are on the way for the treatment of the virus. This review suggests that targeting the host cell surface receptors had more therapeutic potential than targeting protein required for proteolytic activation of the spike protein. Therefore, targeting ACE2, GRP78 and TMPRSS2 have more therapeutic strategic potential as compared with cathepsins, furin and trypsin. Inhibition of entry mechanism is preferable to blocking proteolytic activation of the virus,because it inhibits fusion and further pathogenesis of the virus.

\section{Abbreviations}

ACE2, angiotensin-converting enzyme 2; GRP78, glucose regulated protein 78; RBD, receptor binding domain; SARS-CoV-2, S protein, spike protein; severe acute respiratory syndrome coronavirus-2; TMPRSS2, transmembrane serine protease 2 .

\section{Data Sharing Statement}

Not applicable.

\section{Ethics Approval and Informed Consent}

Not applicable

\section{Consent for Publication}

Not applicable

\section{Acknowledgment}

We would like to forward our grateful to Mr. Tewodros Shibabaw for his proof reading, grammar check and great contribution what we generate this review report.

\section{Author Contributions}

All authors made a significant contribution to the work reported, whether that is in the conception, study design, execution, acquisition of data, analysis and interpretation, or in all these areas; took part in drafting, revising or critically reviewing the article; gave final approval of the version to be published; have agreed on the journal to which the article has been submitted; and agree to be accountable for all aspects of the work.

\section{Funding}

No funding source is available.

\section{Disclosure}

The authors have no conflict of interest to declare for this work.

\section{References}

1. NITULEScU GM, PAUNEScU $\mathrm{H}$, MOScHOS SA, et al. Comprehensive analysis of drugs to treat SARS-CoV-2 infection: mechanistic insights into current COVID-19 therapies. Int $J$ Mol Med. 2020;46(2):467-488. doi:10.3892/ijmm.2020.4608 
2. Jaimes JA, André NM, Chappie JS, Millet JK, Whittaker GR. Phylogenetic analysis and structural modeling of SARS-CoV-2 spike protein reveals an evolutionary distinct and proteolytically sensitive activation loop. J Mol Biol. 2020;432(10):3309-3325.

3. Huang Y, Yang C, Xu X-F, Xu W, Liu S-W. Structural and functional properties of SARS-CoV-2 spike protein: potential antivirus drug development for COVID-19. Acta Pharmacol Sin. 2020;41 (9):1141-1149. doi:10.1038/s41401-020-0485-4

4. Letko M, Marzi A, Munster V. Functional assessment of cell entry and receptor usage for SARS-CoV-2 and other lineage B betacoronaviruses. Nat Microbiol. 2020;5(4):562-569. doi:10.1038/ s41564-020-0688-y

5. Walls AC, Park Y-J, Tortorici MA, Wall A, McGuire AT, Veesler D. Structure, function, and antigenicity of the SARS-CoV-2 spike glycoprotein. Cell. 2020;183(6):1735. doi:10.1016/j.cell.2020.11.032

6. Shang J, Wan Y, Luo C, et al. Cell entry mechanisms of SARS-CoV2. Proc Nat l Acad Sci. 2020;117(21):11727-11734. doi:10.1073/ pnas.2003138117

7. Albini A, Noonan DM, Pelosi G, Di Guardo G, Lombardo M. The SARS-CoV-2 receptor, ACE-2, is expressed on many different cell types: implications for ACE-inhibitor-and angiotensin II receptor blocker-based antihypertensive therapies-reply. Intern Emerg Med. 2020;1-2.

8. Sungnak W, Huang N, Bécavin C, et al. SARS-CoV-2 entry factors are highly expressed in nasal epithelial cells together with innate immune genes. Nat Med. 2020;26(5):681-687. doi:10.1038/s41591020-0868-6

9. Lu M, Uchil PD, Li W, et al. Real-time conformational dynamics of SARS-CoV-2 spikes on virus particles. Cell Host Microbe. 2020;28 (6):880-891. doi:10.1016/j.chom.2020.11.001

10. Jaimes JA, André NM, Chappie JS, Millet JK, Whittaker GR. Phylogenetic analysis and structural modeling of SARS-CoV-2 spike protein reveals an evolutionary distinct and proteolytically-sensitive activation loop. J Mol Biol. 2020;432 (10):3309-3325.

11. Hoffmann M, Hofmann-Winkler H, Smith JC, et al. Camostat mesylate inhibits SARS-CoV-2 activation by TMPRSS2-related proteases and its metabolite GBPA exerts antiviral activity. EBioMedicine. 2021;65:103255. doi:10.1016/j.ebiom.2021.103255

12. Rossi GA, Sacco O, Mancino E, Cristiani L, Midulla F. Differences and similarities between SARS-CoV and SARS-CoV-2: spike receptor-binding domain recognition and host cell infection with support of cellular serine proteases. Infection. 2020;1-5.

13. Wang Q, Zhang Y, Wu L, et al. Structural and functional basis of SARS-CoV-2 entry by using human ACE2. Cell. 2020.

14. Sivaraman H, Er SY, Choong YK, Gavor E, Sivaraman J. Structural Basis of SARS-CoV-2-and SARS-CoV-Receptor Binding and Small-Molecule Blockers as Potential Therapeutics. Annu Rev Pharmacol Toxicol. 2020;61:61. doi:10.1146/annurev-pharmtox -061220-093932

15. Hörnich BF, Großkopf AK, Schlagowski S, et al. SARS-CoV-2 and SARS-CoV spike-mediated cell-cell fusion differ in their requirements for receptor expression and proteolytic activation. $J$ Virol. 2021;95(9). doi:10.1128/JVI.00002-21.

16. Saghazadeh A, Rezaei N. Towards treatment planning of COVID-19: rationale and hypothesis for the use of multiple immunosuppressive agents: anti-antibodies, immunoglobulins, and corticosteroids. Int Immunopharmacol. 2020;84:106560. doi:10.1016/j.intimp.2020. 106560

17. Hasan A, Paray BA, Hussain A, et al. A review on the cleavage priming of the spike protein on coronavirus by angiotensin-converting enzyme-2 and furin. J Biomol Struct Dyn. 2020;1-9.

18. McKee DL, Sternberg A, Stange U, Laufer S, Naujokat C. Candidate drugs against SARS-CoV-2 and COVID-19. Pharmacological Research. 2020;157:104859. doi:10.1016/j.phrs.2020.104859
19. Hoffmann M, Kleine-Weber H, Schroeder S, et al. SARS-CoV-2 cell entry depends on ACE2 and TMPRSS2 and is blocked by a clinically proven protease inhibitor. Cell. 2020;181(2):271-280.e8. doi:10.1016/j.cell.2020.02.052

20. Astuti I. Severe Acute Respiratory Syndrome Coronavirus 2 (SARS-CoV-2): an overview of viral structure and host response. Diabetes Metabol Syndr. 2020;14(4):407-412. doi:10.1016/j. dsx.2020.04.020

21. Yan T, Xiao R, Lin G. Angiotensin-converting enzyme 2 in severe acute respiratory syndrome coronavirus and SARS-CoV-2: a doubleedged sword? FASEB J. 2020;34(5):6017-6026. doi:10.1096/ fj. 202000782

22. Liu Z, Xiao X, Wei X, et al. Composition and divergence of coronavirus spike proteins and host ACE2 receptors predict potential intermediate hosts of SARS-CoV-2. J Med Virol. 2020;92(6):595-601. doi: $10.1002 / j m v .25726$

23. Huang J, Song W, Huang H, Sun Q. Pharmacological therapeutics targeting RNA-dependent RNA polymerase, proteinase and spike protein: from mechanistic studies to clinical trials for COVID-19. J Clin Med. 2020;9(4):1131. doi:10.3390/jcm9041131

24. Zhang H, Penninger JM, Li Y, Zhong N, Slutsky AS. Angiotensinconverting enzyme 2 (ACE2) as a SARS-CoV-2 receptor: molecular mechanisms and potential therapeutic target. Intensive Care Med. 2020;46(4):586-590. doi:10.1007/s00134-020-05985-9

25. Offringa A, Montijn R, Singh S, Paul M, Pinto YM, Pinto-Sietsma* S-J. The mechanistic overview of SARS-CoV-2 using angiotensinconverting enzyme 2 to enter the cell for replication: possible treatment options related to the renin-angiotensin system. Eur Heart J Cardiovasc Pharmacother. 2020;6(5):317-325. doi:10.1093/ehjcvp/pvaa053

26. Ni W, Yang X, Yang D, et al. Role of angiotensin-converting enzyme 2 (ACE2) in COVID-19. Crit Care. 2020;24(1):1-10. doi:10.1186/ s13054-020-03120-0

27. He Y, Zhou Y, Liu S, et al. Receptor-binding domain of SARS-CoV spike protein induces highly potent neutralizing antibodies: implication for developing subunit vaccine. Biochem Biophys Res Commun. 2004;324(2):773-781. doi:10.1016/j.bbrc.2004.09.106

28. Yi C, Sun X, Ye J, et al. Key residues of the receptor binding motif in the spike protein of SARS-CoV-2 that interact with ACE2 and neutralizing antibodies. Cell Mol Immunol. 2020;17(6):621-630. doi:10.1038/s41423-020-0458-Z

29. He Y, Lu H, Siddiqui P, Zhou Y, Jiang S. Receptor-binding domain of severe acute respiratory syndrome coronavirus spike protein contains multiple conformation-dependent epitopes that induce highly potent neutralizing antibodies. $J$ Immunol. 2005;174(8):4908-4915. doi:10.4049/jimmunol.174.8.4908

30. Ibrahim IM, Abdelmalek DH, Elshahat ME, Elfiky AA. COVID-19 spike-host cell receptor GRP78 binding site prediction. $J$ Infect. 2020;80(5):554-562. doi:10.1016/j.jinf.2020.02.026

31. Elfiky AA, Baghdady AM, Ali SA, Ahmed MI. GRP78 targeting: hitting two birds with a stone. Life Sci. 2020;260:118317. doi:10.1016/j.lfs.2020.118317

32. Palmeira A, Sousa E, Köseler A, et al. Preliminary virtual screening studies to identify GRP78 inhibitors which may interfere with SARS-CoV-2 infection. Pharmaceuticals. 2020;13(6):132. doi:10.3390/ ph13060132

33. Elfiky AA, Ibrahim IM, Ismail AM, Elshemey WM. A possible role for GRP78 in cross vaccination against COVID-19. J Infect. 2020.

34. Patel S, Srivastav AK, Gupta SK, et al. Carbon nanotubes for rapid capturing of SARS-COV-2 virus: revealing a mechanistic aspect of binding based on computational studies. RSC Adv. 2021;11 (10):5785-5800. doi:10.1039/D0RA08888A

35. Arokiyaraj S, Stalin A, Kannan BS, Shin H. Geranii Herba as a Potential Inhibitor of SARS-CoV-2 Main 3CLpro, Spike RBD, and Regulation of Unfolded Protein Response: an In Silico Approach. Antibiotics. 2020;9(12):863. doi:10.3390/antibiotics 9120863 
36. Köseler A, Sabirli R, Gören T, Türkçüer I, Kurt Ö. Endoplasmic reticulum stress markers in SARS-COV-2 infection and pneumonia: case-control study. vivo. 2020;34(3 suppl):1645-1650. doi:10.21873/ invivo. 11956

37. Law JN, Tasnina N, Kshirsagar M, et al. Identifying Human interactors of SARS-CoV-2 proteins and drug targets for COVID-19 using network-based label propagation. arXiv preprint arXiv:200601968. 2020.

38. Gelman R, Bayatra A, Kessler A, Schwartz A, Ilan Y. Targeting SARS-CoV-2 receptors as a means for reducing infectivity and improving antiviral and immune response: an algorithm-based method for overcoming resistance to antiviral agents. Emerging MicrobesInfect. 2020;1-21.

39. Quimque MTJ, Notarte KIR, Fernandez RAT. et al. Virtual screening-driven drug discovery of SARS-CoV2 enzyme inhibitors targeting viral attachment, replication, post-translational modification and host immunity evasion infection mechanisms. J Biomol Struct Dyn;2020. 1-18. doi:10.1080/07391102.2020.1776639

40. Rayner JO, Roberts RA, Kim J, et al. AR12 (OSU-03012) suppresses GRP78 expression and inhibits SARS-CoV-2 replication. Biochem Pharmacol. 2020;182:114227. doi:10.1016/j.bcp.2020.114227

41. Hoffmann M, Kleine-Weber H, Pöhlmann S. A multibasic cleavage site in the spike protein of SARS-CoV-2 is essential for infection of human lung cells. Mol Cell. 2020;78(4):779-784.e5. doi:10.1016/j. molcel.2020.04.022

42. Nersisyan S, Shkurnikov M, Turchinovich A, Knyazev E, Tonevitsky A. Integrative analysis of miRNA and mRNA sequencing data reveals potential regulatory mechanisms of ACE2 and TMPRSS2. PLoS One. 2020;15(7):e0235987. doi:10.1371/journal. pone. 0235987

43. Uludağ H, Parent K, Aliabadi HM, Haddadi A. Prospects for RNAi therapy of COVID-19. Front Bioeng Biotechnol. 2020;8:916. doi:10.3389/fbioe.2020.00916

44. Simmons G, Zmora P, Gierer S, Heurich A, Pöhlmann S. Proteolytic activation of the SARS-coronavirus spike protein: cutting enzymes at the cutting edge of antiviral research. Antiviral Res. 2013;100 (3):605-614. doi:10.1016/j.antiviral.2013.09.028

45. Heurich A, Hofmann-Winkler H, Gierer S, Liepold T, Jahn O, Pöhlmann S. TMPRSS2 and ADAM17 cleave ACE2 differentially and only proteolysis by TMPRSS2 augments entry driven by the severe acute respiratory syndrome coronavirus spike protein J Virol. 2014;88(2):1293-1307. doi:10.1128/JVI.02202-13

46. Shen LW, Mao HJ, Wu YL, Tanaka Y, Zhang W. TMPRSS2: a potential target for treatment of influenza virus and coronavirus infections. Biochimie. 2017;142:1-10. doi:10.1016/j.biochi.2017.07.016

47. Tang T, Bidon M, Jaimes JA, Whittaker GR, Daniel S. Coronavirus membrane fusion mechanism offers a potential target for antiviral development. Antiviral Res. 2020;178:104792. doi:10.1016/j. antiviral.2020.104792

48. Jaimes JA, Millet JK, Whittaker GR. Proteolytic cleavage of the SARS-CoV-2 spike protein and the role of the novel S1/S2 site. Iscience. 2020;23(6):101212. doi:10.1016/j.isci.2020.101212

49. Tang T, Jaimes JA, Bidon MK, Straus MR, Daniel S, Whittaker GR. Proteolytic activation of SARS-CoV-2 spike at the S1/S2 boundary: potential role of proteases beyond furin. ACS Infect Dis. 2021;7 (2):264-272. doi:10.1021/acsinfecdis.0c00701

50. Padmanabhan P, Desikan R, Dixit N Targeting TMPRSS2 and Cathepsin $\mathrm{B} / \mathrm{L}$ together may be synergistic against SARS-CoV-2 infection. 2020.

51. Ou X, Liu Y, Lei X, et al. Characterization of spike glycoprotein of SARS-CoV-2 on virus entry and its immune cross-reactivity with SARS-CoV. Nat Commun. 2020;11(1):1-12. doi:10.1038/s41467020-15562-9

52. Sasaki M, Uemura K, Sato A, et al. SARS-CoV-2 variants with mutations at the S1/S2 cleavage site are generated in vitro during propagation in TMPRSS2-deficient cells. PLoS Pathog. 2021;17(1): e1009233. doi:10.1371/journal.ppat.1009233
53. Katopodis P, Anikin V, Randeva HS, et al. Pan-cancer analysis of transmembrane protease serine 2 and cathepsin $\mathrm{L}$ that mediate cellular SARS-CoV-2 infection leading to COVID-19. Int $J$ Oncol. 2020;57(2):533-539. doi:10.3892/ijo.2020.5071

54. Bittmann S, Weissenstein A, Villalon G, Moschuring-Alieva E, Luchter E. Simultaneous Treatment of COVID-19 With Serine Protease Inhibitor Camostat and/or Cathepsin L Inhibitor? J Clin Med Res. 2020;12(5):320. doi:10.14740/jocmr4161

55. Sacco MD, Ma C, Lagarias $\mathrm{P}$, et al. Structure and inhibition of the SARS-CoV-2 main protease reveal strategy for developing dual inhibitors against Mpro and cathepsin L. Sci Advances. 2020;6(50): eabe0751. doi:10.1126/sciadv.abe 0751

56. Millet JK, Whittaker GR. Host cell proteases: critical determinants of coronavirus tropism and pathogenesis. Virus Res. 2015;202:120-134. doi:10.1016/j.virusres.2014.11.021

57. Ganesan SK, Venkatratnam P, Mahendra J, Devarajan N. Increased mortality of COVID-19 infected diabetes patients: role of furin proteases. Int $J$ Obes. 2020;1-3.

58. Vankadari N. Structural interactions between pandemic SARS-CoV-2 spike glycoprotein and human Furin protease. bioRxiv. 2020.

59. Anand P, Puranik A, Aravamudan M, Venkatakrishnan A, Soundararajan V. SARS-CoV-2 strategically mimics proteolytic activation of human ENaC. Elife. 2020;9:e58603. doi:10.7554/eLife.58603

60. Papa G, Mallery DL, Albecka A, et al. Furin cleavage of SARS-CoV2 Spike promotes but is not essential for infection and cell-cell fusion. PLoS Pathog. 2021;17(1):e1009246. doi:10.1371/journal. ppat. 1009246

61. Tang T, Jaimes JA, Bidon MK, Straus MR, Daniel S, Whittaker GR. Proteolytic activation of the SARS-CoV-2 spike S1/S2 site: a re-evaluation of furin cleavage. bioRxiv. 2020.

62. Bestle D, Heindl MR, Limburg H, et al. TMPRSS2 and furin are both essential for proteolytic activation of SARS-CoV-2 in human airway cells. Life Scialliance. 2020;3(9):9. doi:10.26508/ 1sa.202000786

63. Örd M, Faustova I, Loog M. The sequence at Spike S1/S2 site enables cleavage by furin and phospho-regulation in SARS-CoV2 but not in SARS-CoV1 or MERS-CoV. Sci Rep. 2020;10(1):1-10. doi:10.1038/s41598-020-74101-0

64. Cheng Y-W, Chao T-L, Li C-L, et al. Furin Inhibitors Block SARS-CoV-2 spike protein cleavage to suppress virus production and cytopathic effects. Cell Rep. 2020;33(2):108254. doi:10.1016/j. celrep.2020.108254

65. Artigas L, Coma M, Matos-Filipe P, et al. In-silico drug repurposing study predicts the combination of pirfenidone and melatonin as a promising candidate therapy to reduce SARS-CoV-2 infection progression and respiratory distress caused by cytokine storm. PLoS One. 2020;15(10):e0240149. doi:10.1371/journal. pone. 0240149

66. Aoe T. Pathological aspects of COVID-19 as a conformational disease and the use of pharmacological chaperones as a potential therapeutic strategy. Front Pharmacol. 2020;11:1095. doi:10.3389/ fphar.2020.01095

67. Sabirli R, Koseler A, Goren T, Turkcuer I, Kurt O. High GRP78 levels in Covid-19 infection: a case-control study. Life Sci. 2020;265:118781. doi:10.1016/j.lfs.2020.118781

68. Zhu Y, Li J, Pang Z. Recent insights for the emerging COVID-19: drug discovery, therapeutic options and vaccine development. Asian J Pharm Sci. 2020.

69. Allam L, Ghrifi F, Mohammed H, et al. Targeting the GRP78-Dependant SARS-CoV-2 cell entry by peptides and small molecules. Bioinform Biol Insights. 2020;14:1177932220965505. doi:10.1177/1177932220965505

70. Mackey K, King VJ, Gurley S, et al. Risks and impact of angiotensin-converting enzyme inhibitors or angiotensin-receptor blockers on SARS-CoV-2 infection in adults: a living systematic review. Ann Intern Med. 2020. 
71. Xu J, Teng Y, Shang L, et al. The effect of prior ACEI/ARB treatment on COVID-19 susceptibility and outcome: a systematic review and meta-analysis. Clin Infect Dis. 2020.

72. Amin SA, Jha T. Fight against novel coronavirus: a perspective of medicinal chemists. Eur J Med Chem. 2020;201:112559. doi:10.1016/j.ejmech.2020.112559

73. Goel N, Bhyan SJ, Bhyan B, Jain A, Kumari A, Sharma G. The Role of ACE2 Receptor and its Age Related Immunity in Covid-19.

74. Chaudhry SN, Hazafa A, Mumtaz M, et al. New insight on possible vaccine development against SARS-CoV-2. Life Sci. 2020;260:118421. doi:10.1016/j.1fs.2020.118421

75. Yu J, Tostanoski LH, Peter L, et al. DNA vaccine protection against SARS-CoV-2 in rhesus macaques. Science. 2020;369(6505):806-811. doi: $10.1126 /$ science.abc6284

76. Amanat F, Krammer F. SARS-CoV-2 vaccines: status report. Immunity. 2020;52(4):583-589. doi:10.1016/j.immuni.2020.03.007

77. Keech C, Albert G, Cho I, et al. Phase 1-2 trial of a SARS-CoV-2 recombinant spike protein nanoparticle vaccine. $N$ Engl $J$ Med. 2020;383(24):2320-2332. doi:10.1056/NEJMoa2026920

78. Leach DA, Isac A-M, Bevan CL, Brooke GN. TMPRSS2, required for SARS-CoV-2 entry, is downregulated in lung cells by enzalutamide, a prostate cancer therapeutic. 2020.

79. Shetty R, Ghosh A, Honavar SG, Khamar P, Sethu S. Therapeutic opportunities to manage COVID-19/SARS-CoV-2 infection: present and future. Indian J Ophthalmol. 2020;68(5):693. doi:10.4103/ijo. IJO $639 \_20$

80. Bilal M, Iqbal HM. Recent advances in therapeutic modalities and vaccines to counter COVID-19/SARS-CoV-2. Hum Vaccin Immunother. 2020;1-9.

81. Samrat SK, Tharappel AM, Li Z, Li H. Prospect of SARS-CoV-2 spike protein: potential role in vaccine and therapeutic development. Virus Res. 2020;198141.
82. Stopsack KH, Mucci LA, Antonarakis ES, Nelson PS, Kantoff PW. TMPRSS2 and COVID-19: serendipity or opportunity for intervention? Cancer Discov. 2020;10(6):779-782. doi:10.1158/2159-8290.CD-200451

83. Uno Y. Camostat mesilate therapy for COVID-19. Intern Emerg Med. 2020;1-2.

84. Sternberg A, McKee DL, Naujokat C. Novel drugs targeting the SARS-CoV-2/COVID-19 machinery. Curr Top Med Chem. 2020;20 (16):1423-1433. doi:10.2174/1568026620999200517043137

85. Breining P, Frølund AL, Højen JF, et al. Camostat mesylate against SARS-CoV-2 and COVID-19-rationale, dosing and safety. Basic Clin Pharmacol Toxicol. 2020.

86. Scavone C, Brusco S, Bertini M, et al. Current pharmacological treatments for COVID-19: what's next? Br J Pharmacol. 2020;177 (21):4813-4824. doi:10.1111/bph.15072

87. Ragia G, Manolopoulos VG. Inhibition of SARS-CoV-2 entry through the ACE2/TMPRSS2 pathway: a promising approach for uncovering early COVID-19 drug therapies. Eur J Clin Pharmacol. 2020;1-8.

88. Wambier CG, Goren A, Vaño-Galván S, et al. Androgen sensitivity gateway to COVID -19 disease severity. Drug Dev Res. 2020;81 (7):771-776. doi:10.1002/ddr.21688

89. Qing E, Gallagher T. SARS coronavirus redux. Trends Immunol. 2020;41(4):271-273. doi:10.1016/j.it.2020.02.007

90. Zang R, Castro MFG, McCune BT, et al. TMPRSS2 and TMPRSS4 promote SARS-CoV-2 infection of human small intestinal enterocytes. Sci Immunol. 2020;5(47):47. doi:10.1126/sciimmunol. abc3582
Infection and Drug Resistance

\section{Publish your work in this journal}

Infection and Drug Resistance is an international, peer-reviewed openaccess journal that focuses on the optimal treatment of infection (bacterial, fungal and viral) and the development and institution of preventive strategies to minimize the development and spread of resistance. The journal is specifically concerned with the epidemiology of

\section{Dovepress}

antibiotic resistance and the mechanisms of resistance development and diffusion in both hospitals and the community. The manuscript management system is completely online and includes a very quick and fair peerreview system, which is all easy to use. Visit http://www.dovepress.com/ testimonials.php to read real quotes from published authors. 